\title{
TEMPORAL AND SPATIAL VARIATIONS IN HEAT CONTENT OF A FRENCH POND
}

\author{
Quentin CHOFFEL ${ }^{1}$, Laurent TOUCHART ${ }^{1}$, Pascal BARTOUT ${ }^{1}$, \\ Mohammad AL DOMANY
}

DOI: 10.21163/GT_2017.121.02

\begin{abstract}
:
Ponds are regarded as small waterbodies with a depth of less than $6 \mathrm{~m}$ and an area of less than 100 ha. In the Limousine region (France), they usually bar small incised valleys, giving them a complex morphology. This morphology may separate the pond in several basins, as for the pond of La Ramade $\left(45^{\circ} 47^{\prime} 04.3^{\prime \prime} \mathrm{N} ; 2^{\circ} 25^{\prime} 30.7^{\prime \prime} \mathrm{E}\right)$, theoretically suitable for a spatial variation of temperature. The pond has been implemented with 4 moorings chains composed of automatic thermistors, measuring the temperature every hour from the surface to the bottom. A meteorological station has been deployed close to the pond, in order to gather very precise meteorological information, in addition to the map of fetch and bathymetry. The working hypothesis is that even small waterbodies present a spatial heterogeneity of water temperature, so that the classic measurements only at one point give approximate values. The aim is to get a 3D overview of the thermal dynamic of a small waterbody for the purpose of a better understanding of its temperature dynamic, with heat content's approach. In polymictic waterbody, the temporal but as well spatial variations of the heat content are together numerous and varied. The first results bring us the autonomous function of the bays and sheltering places, while the open water has a predictable function. Some parameters such as the fetch, the sheltering by vegetation or the bathymetry plays a more or less important role in the particularity of each basin. The heat content's methodology shall be improved by consideration of the spatial variation of the pond's temperature.
\end{abstract}

Key-words: Heat content, Water temperature, Pond, Spatial variation, Water Framework Directive.

\section{INTRODUCTION}

The heat content of lakes and thermal properties is well studied since the beginning of the $20^{\text {th }}$ century (Birge, 1909; Wedderburn, 1910; Birge \& Juday, 1914; Saur \& Anderson, 1956; Gorham, 1964). Except-for the biological survey (Williams et al, 2003; Downing, 2010; Céréghino et al, 2013), ponds are studied less than lakes, probably because of their small size and artificial creation. They are frequently regarded as a homogeneous epilimnion or "mixed-layer" (Imberger, 1985) of a lake. Some studies carried on the thermal properties of ponds, especially on a vertical scale (Touchart, 2002; Folkard et al, 2007; Touchart, 2016), revealed the presence of a possible strong thermocline on several days. French ponds are located in several places, depending on their variety. Some ponds are located in important wetlands, without any rivers, or even in the flood plain of biggest rivers. They are the most famous and well known. Others ponds are located in the headwater of small stream with a temporary flow during thermic summer.

\footnotetext{
${ }^{1}$ Université d'Orléans, Département de Géographie, 45065 Orléans, France, quentin.choffel@gmail.com, Laurent.touchart@univ-orleans.fr, pascal.bartout@univ-orleans.fr, mohammad-aldomany@hotmail.com.
} 
In that case, ponds are manmade with the aim of stocking water used for fishing, agricultural, industrial, and even recreational reasons (Bartout, 2015). These ponds are our main focus and La Ramade pond is one of these manmade ponds located in headwater stream.

The issue of the stream temperature increase in headwater is frequently awarded to small waterbodies baring a stream, i.e. ponds. In the context of the sustainable management of water resources set by the Water Framework Directive (WFD) of 23 October 2000, the French Water and Aquatic environmental Law of 30 December 2006, ponds with an area greater than 50 ha can be concerned. In that case, temperature measurements are carried out, usually on one single point. Most of the studies, especially unpublished papers of the French authorities, are focused on the temperature continuum stream-pond-stream, without knowing the heat content behaviour inside the pond. In lake's study, the horizontal scale getting more important and some studies took spatial measurements about great lakes (Xing et al, 2012; Wang et al, 2014), the embayment of lakes, especially about lake Ontario (Rueda \& Cowen, 2005; Murphy et al, 2012) or also about a big mire system (Ramos, 2012), without taking into consideration the ponds, where the application should be the most achievable. It is a very important point regarding the ponds, where it is possible to choose the depth of the outflow (monk, weir...) or to change the localization of the outfall in order to decrease the temperature's impact on downstreams.

Small waterbodies are more numerous than lakes, at France's scale (Bartout \& Touchart, 2013) but also on a global scale (Downing, 2010; Verpoorter et al, 2014; Bartout et al, 2015). The thermic operation of a lake is quite different, focusing on the surface's temperature and the depth of the thermocline (Liu et al, 2014). It is more complex in polymictic waterbodies, where diurnal and temporary thermoclines are varying very often. Lakes and ponds are sensible to the global warming, felt in their heat budget, sensible to the climatic variations, especially for shallow waterbodies (i.e. ponds). The increase in the maximal air temperature should cause an increase in the heat content of the waterbodies and therefore, may be an issue to the fish population. The wind plays a major role in the heat budget and to spatial heterogeneity of the waterbody. Furthermore, heat budget is a mean indictor of the influence of waterbodies on the local climate. With more than 550000 waterbodies in France (Bartout \& Touchart, 2013), their heat budget is important to be known.

This research focuses on the thermal dynamic and heat budget of a pond, at different spatial and temporal scales. The pond has been instrumented with 4 thermistor chains in different basins, delimited by the map of fetch and bathymetry. The aim is to analyse the spatial variability of the heat content and to know if it is suitable to take temperature measurements only at a single point. Two heat budgets have been calculated according to the traditional method (BT1) and to the new method from the 4 delimited basins (BT2).

\section{STUDY SITE}

The pond of "la Ramade" is located in the Limousine region of France, in the "plateau de Millevaches". It is one of the greatest ponds in Limousin with an area of 62 ha. The mean depth is about $1 \mathrm{~m}$ and the maximal depth is rarely up to $3 \mathrm{~m}$. This site has been chosen because of its very complex morphology, with an important length of the shoreline (Shoreline development index of 6.01). The turbidity of the pond is high, with Secchi disc depth maximum of $0.75 \mathrm{~m}$ in May and $0.55 \mathrm{~m}$ in August. It is located on a substrate of plutonic rocks, in the old mountain of Massif Central, at an altitude of $736 \mathrm{~m}$.-According to 
Joly's climatic typology (Joly et al, 2010), La Ramade pond is at the border between "mountain climate" and "semi continental climate and marge of the mountains". The mean precipitations are around 1000 to $1100 \mathrm{~mm} /$ year according to a local MeteoFrance meteorological station. The pond of la Ramade bars two streams of order 2 in the Strahler classification: the stream of Manaly in the Western part and the stream of Chavanon to the North. The mean retention time of the pond has been estimated at 21 days (Humbert, 2014).

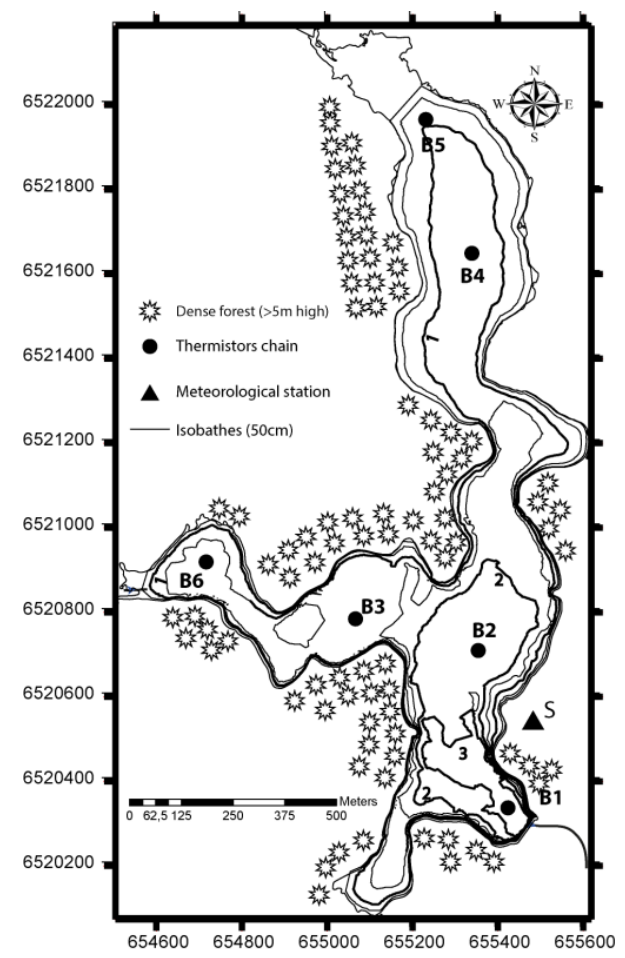

Fig. 1 Bathymetry map and localisation of the thermal chain (Humbert, 2014, changed). Coordinates in RGF93.

The long and narrow morphology of La Ramade pond is very interesting to be thermally studied. Elongated in the South-North direction, a bend in the central part breaks the fetch that, to a certain extent, divides the pond in two main distinguished, although permanently linked, basins (Fig.1).

\section{METHODOLOGY}

The methodology of vertical thermal analysis of a pond is widely used by Touchart (2002, 2016) in France and Folkard et al (2007) in England. The present methodology is enhanced by the addition of the spatial scale, with the implementation of four thermal chains instrumented with 10 to 4 thermometers, measuring every hour the temperature of the water, from the surface to the depth. With the hypothesis that the bathymetry and the run of the wind (i.e. fetch) on the waterbody play a major role (Birge, 1909; Birge, 1916; Imberger \& Parker, 1985; Markfort et al, 2010), four basins have been delimited according to the bathymetry map (Humbert, 2014 changed) and the Mean Potential Fetch (MPF) map 
(Papon, 2007). Due to the remoteness of the closest meteorological station and the possible particularity of the local climate due to the topography, a meteorological station Vintage pro 2 have been disposed close to the lake.

\subsection{Study measurements}

A meteorological station Vintage pro 2 is located a few meters away from the pond, on the roof of a habitation (around $3 \mathrm{~m}$ high). The console allows the instant display of outdoor and indoor temperatures, dew point temperature, the wind chill temperature, degree of indoor and outdoor humidity, daily and cumulative rainfall, and speed and wind direction. The station is linked with the computer by an external console. Everything is easily managed by the WeatherLink software.

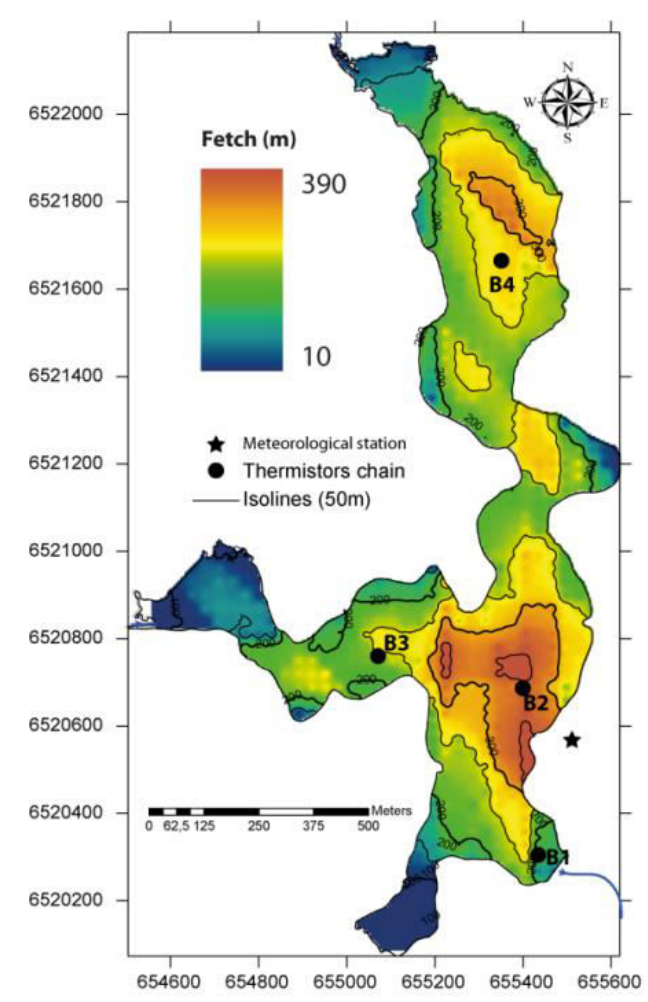

Fig. 2 Map of the mean potential fetch on la Ramade pond.

The research is based on the water temperature, main factor in the aquatic life (Wetzel, 1983), with the implementation of Tinytag Data Loggers (range of -40 to $85^{\circ} \mathrm{C}$ ) and Hobo Water Temp Pro V2 (range of -20 to $50^{\circ} \mathrm{C}$ ), measuring the temperature every hour on every chain around the pond. The precision is respectively about 0.01 and $0.02{ }^{\circ} \mathrm{C}$ and the water resistance is from 15 to $150 \mathrm{~m}$ depth. As a precaution, every chain is instrumented with only one type of thermistor in order to reduce the potential precision differences. The data are directly gathered from the boat once a month. During the study period (03/03/2016 to 02/08/2016), on the pond La Ramade, 98469 temperature data have been implemented and analyzed. 


\subsection{Spatial distribution of wind: map of fetch}

The early work of Birge, at the beginning of the 19th century, has demonstrated the major role of the external forces into the thermal dynamic. His studies focused on the role of the wind, so far disregarded (Birge, 1909; Birge \& Juday, 1914). As developed by Papon (2007) in his thesis, the map of fetch is an important element of the thermal property of a waterbody. This map consists in drawing the maximum run of the wind at every point of the lake (resolution of $10 \mathrm{~m}$ ). This operation can be done automatically according to tools on the GIS software, but when the shore is complex, a few manipulations are necessary (Papon, 2007). On La Ramade pond, the treatment has been done manually, due to the very steep morphology. An extrapolation of the point derived from the lines, where the MPF is calculated taking the mean fetch over the pond, after extrapolation. The mean potential fetch map is an indicator of the wind heterogeneity over a waterbody (Fig.2).

The wind blow is heterogeneous on the pond, with some parts sheltered by the wind and others very well exposed in spite of their small size and consequently the very short fetch. The MPF map can be compared with the thermic dynamic of the pond (Wedderburn Number, Brunt-Väisälä Frequency, Stability of smith...). It will be the study case of a further study.

\subsection{Methods for calculating the heat budget}

The heat budget, introduced by Forel (1892), is the main part of the lake temperature's study over the last century. The methodology for calculating the heat budget has been widely developed by Birge \& Juday (1914), enhanced by Ragotzkie (1978), Hutchinson (1957), Stewart (1973) on lakes and Touchart $(2002,2016)$ on ponds. The volume of each layer is multiplied by the represented temperature, every hour. Thermistors are located every $25 \mathrm{~cm}$ until $1.5 \mathrm{~m}$, and then every $50 \mathrm{~cm}$ from the depth to the bottom. The volume of the pond has been taken from the bathymetry map (Humbert, 2014 changed), made by a depth sounder in spring 2013. The vertical component, from the bathymetry, and the horizontal component of the thermal chain give a three dimension overview of the thermal component of the pond. The heat content of every layer is calculated every hour, with the possibility of several heat budgets' calculation, cyclic or acyclic, as daily or weekly heat budget in addition to the traditional heat budgets (Forel, 1892; Birge, 1915; Hutchinson, 1957). The operations have been done with ArcGis10 software for the bathymetry, the basins separation and Surfer11 software for the calculations, giving the volume of the concerned layer. For this study, the heat budget is calculated from the thermal chain localised few meters before the dam (B1), at the deepest point of the waterbody, following the traditional method. This heat budget is named BT1.

Table 1.

Comparison of the four basins.

\begin{tabular}{|l|r|r|r|r|r|}
\hline \multicolumn{1}{|c|}{ Basins } & area $\left.\mathbf{( c m}^{2}\right)$ & Volume (m3) & $\begin{array}{c}\text { max } \\
\text { depth } \\
(\mathbf{m})\end{array}$ & $\begin{array}{c}\text { mean } \\
\text { depth }(\mathbf{m})\end{array}$ & Mean fetch (m) \\
\hline Digue & 798010000 & 126652 & 3 & 1,38 & 192 \\
\hline Central & 1637830000 & 236060 & 2,48 & 1,27 & 276 \\
\hline Manaly & 1005120669 & 80514 & 1,3 & 0,7 & 187 \\
\hline Nord & 1941500694 & 91928 & 1,05 & 0,41 & 233 \\
\hline
\end{tabular}




\subsection{Meteorological data}

The site is widely windy, with a weak but almost permanent wind blowing over the pond. The wind's dominant directions are from the West, and more precisely from the South-West quart (29\%) and the North-West quart (35\%). It is an oceanic wind influence, from the Atlantic Ocean located more than $250 \mathrm{~km}$ away. The precipitations were quite frequent and durable, but not very intense during this period. During the study period, the climate was particular with a rainy and cold springtime and a very warm and dry month of July (Fig. 3). This particularity shows very different climatic stages, which are found into the heat content of the pond. From 31/05 to 21/06 a technical failure did not enable the use of the meteorological data. 1872 hourly data are available for this study, from 26/04 to $02 / 08$.
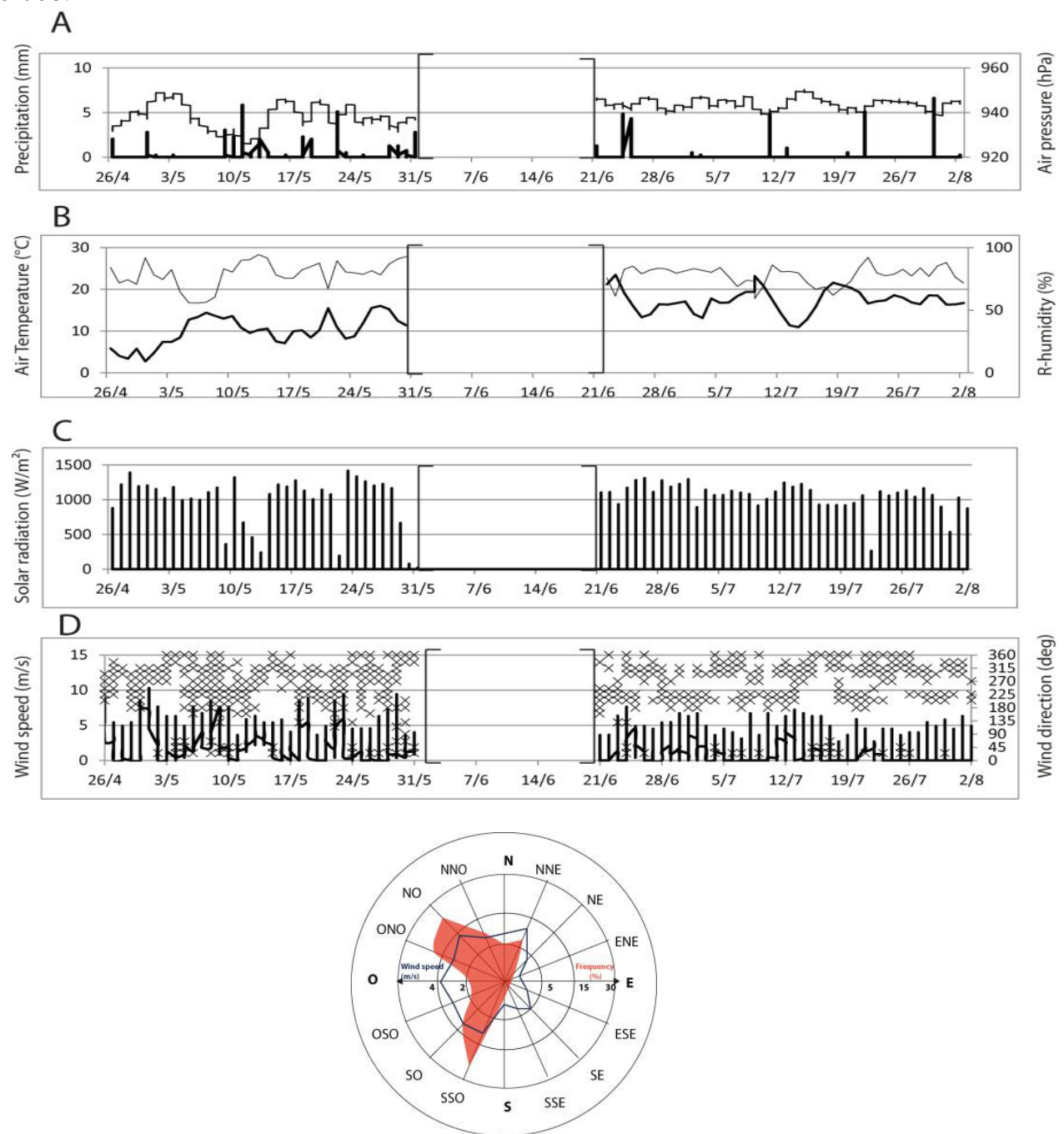

Fig. 3. A, B, C, D: meteorological conditions from the Vantage Pro 2 station. 26/04/2016 to 02/08/2016. Below: wind rose from the Vantage Pro 2 station; data from 26/04/2016 to 31/05/2016 and 21/06/2016 to 02/08/2016. 


\section{RESULTS}

\subsection{Thermal behavior}

The thermal behaviour of the pond is determined by the four thermal chains disposed all around the pond. The mean monthly or even daily temperature at the several locations is quite the same. The main differences are measured with hourly data, where some external or internal factors can modify the temperature within a few hours. The temperature in a polymictic lake is changing fast as shown on the Fig. 4.

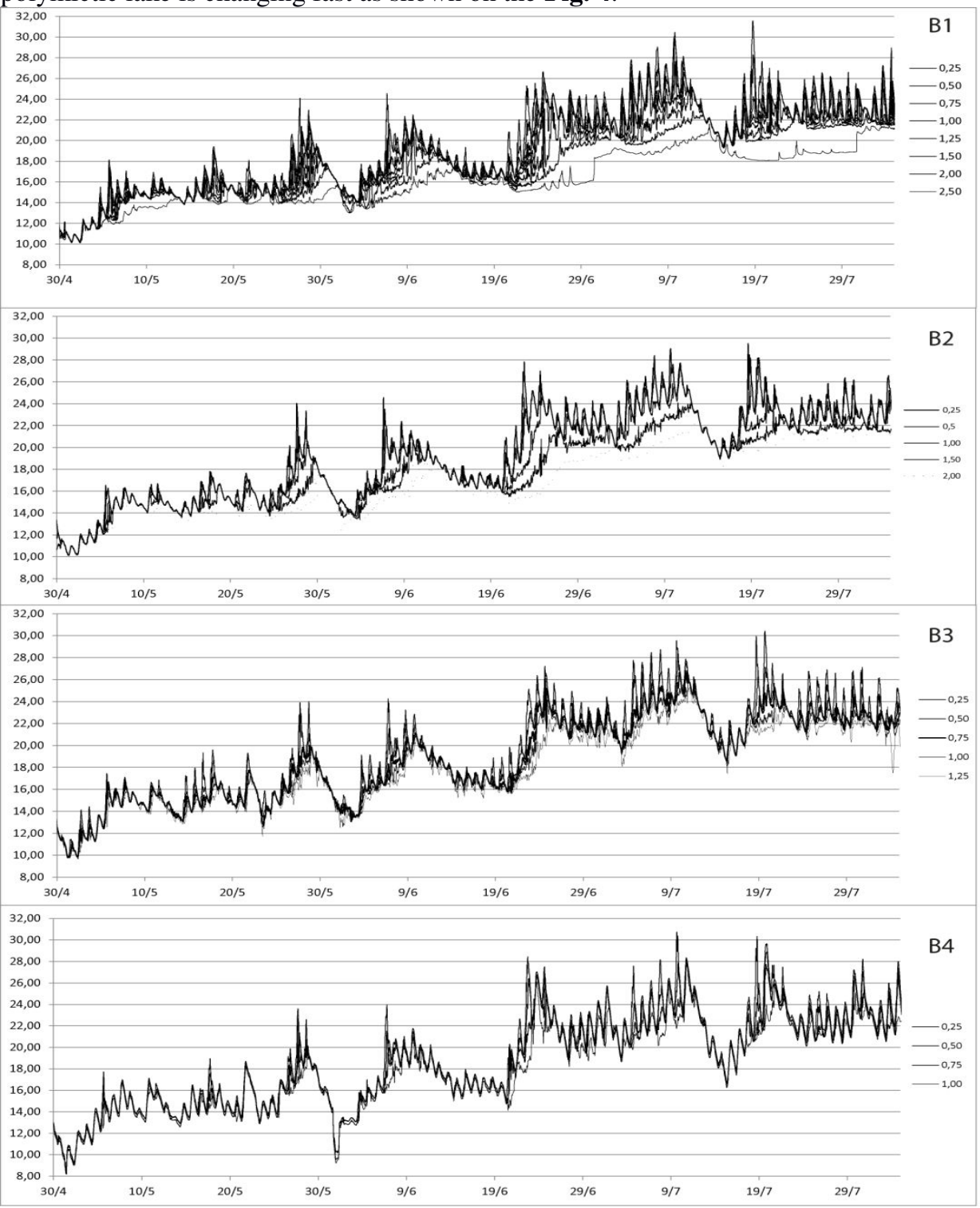

Fig. 4. Thermal behaviour of the La Ramade pond on the four thermal chains. 30/04/2016 to 02/08/2016. 
The deepest part of the pond (B1 \& B2) is weakly stratified during spring, with the appearance of diurnal stratification during shiny and calm weather. During summer, the stratification is stronger and can remain for several weeks ( 3 weeks maximum here). The onset of a strong wind and a decrease in the temperature lead to a break of the thermal stratification. In the two other basins, the stratification is weaker during one day or a few days for the B3. B3 is more strongly stratified and warmer than in the basin 4, yet a bit shallower.

The four basins have different thermal behaviour, making a difference in the heat content of the pond between the traditional and the newly integrated methods of calculating. The temperature is directly linked to the heat content. A difference in temperature between several places in the pond induces to a difference in heat content. From $30^{\text {th }}$ of April to $2^{\text {nd }}$ of August, the differences in temperature within the pond can be important. Some places as B1 and B3 have reached the temperature of $30^{\circ} \mathrm{C}$ or more, while it never happened in the central basin. The bottom temperature is changing manly due to the bathymetry and exposure to the wind, with the phenomenon of small upwelling.

\subsection{Heat content}

\subsubsection{Study period (03/03/2016 to 02/08/2016)}

The heat content is the amount of temperature on the whole waterbody, with a three dimensional scale. The annual heat budget of La Ramade pond, i.e. "the total of amount of heat that enters the lake between the time of its lowest and its highest heat content" (Hutchinson, 1957, p. 493), is $2462 \mathrm{cal} / \mathrm{cm}^{2}$ (The study period do not include the whole year. The annual heat budget can be different.). This annual heat budget is very close to that one of a close pond of Les Oussines: 2485 (Touchart, 2016, data from 2002).

During hypothermia or small and quick stratifications, the heat budget increases slightly. It can also decrease during a few days, according to the meteorological conditions. During the stage of thermic stratifications, the heat budget increases considerably during several days to several weeks and decreases during temporal homothermy (Fig. 5).

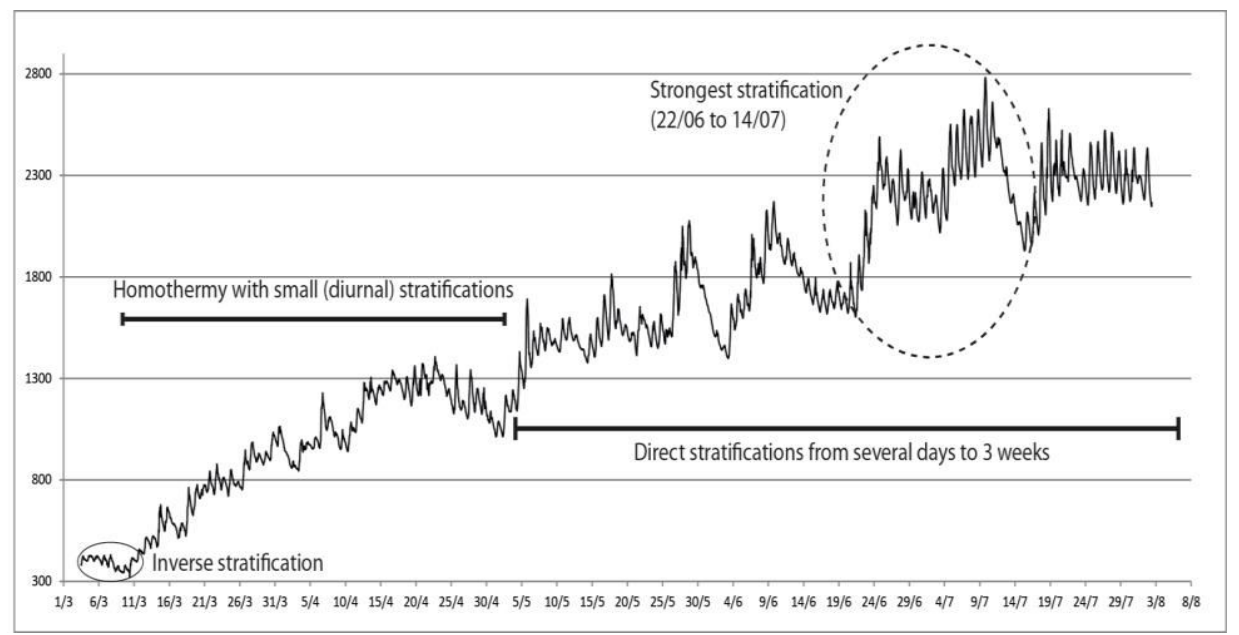

Fig. 5. Heat content of La Ramade pond from 03/03/2016 to 02/08/2016. 


\subsubsection{Percentage of difference}

From the end of May, at the beginning of the summer, the differences between the two heat budgets took another shape. The values of the differences are less sharp, with a positive maximum of $10.7 \%$ and negative maximum of $-8 \%$. The mean gap is $2.16 \%$, inferior to the first part of the study period (Fig.6). The curve is smoother with longer periods of positive differences and shorter periods of negative maximum.

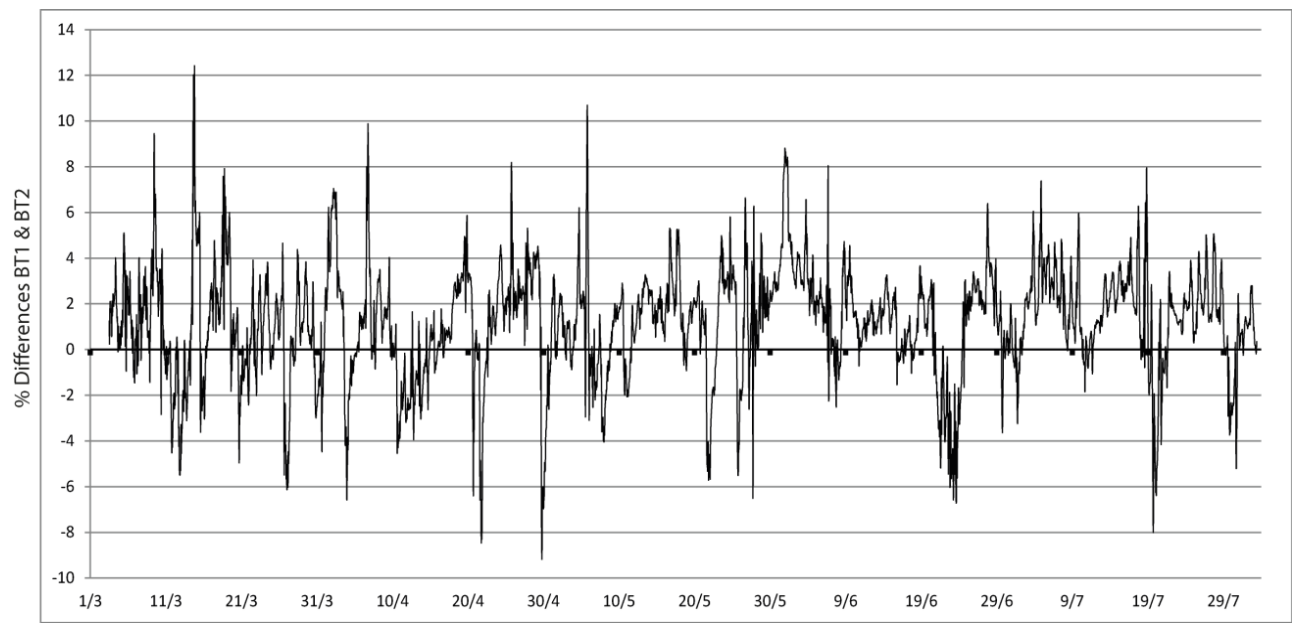

Fig. 6. Percentage of difference between BT1 and BT2 during the whole study period.

The differences can be punctually or temporally high. The difference in annual heat budgets is weak, with BT1 about $2462 \mathrm{cal} / \mathrm{cm}^{2}$ and $2329 \mathrm{cal} / \mathrm{cm}^{2}$ from BT2. However, the minimum occurred on $09 / 03 / 2016$ for BT1 while it is one day later $(10 / 03 / 2016)$ for BT2. The maxima occurred at the same time $(02 / 08 / 2016,10: 00)$ but are limited by the period of study, stopping at this moment.

\subsubsection{Study period: 17 to 21 July}

The focus is on a short period from the $17^{\text {th }}$ to $21^{\text {st }}$ of July, where the positive maximum $\left(18^{\text {th }}\right.$ of July) and the negative maximum $\left(19^{\text {th }}\right.$ of July) from the second part of the study period, occurred. In only $24 \mathrm{~h}$, the negative maximum and the positive maximum were reached, during a stable period of thermal stratification.

From the $17 / 7$ to the $21 / 7$, the outdoor temperature was quite similar, from $28^{\circ} \mathrm{C}\left(17^{\text {th }}\right.$ and $21^{\text {st }}$ of July) to $34^{\circ} \mathrm{C}\left(19^{\text {th }}\right.$ of July). The wind is the only main factor varying considerably during this time. The variation of the wind speed went from a maximum of $0.4 \mathrm{~m} / \mathrm{s}$ the $18^{\text {th }}$ of July and $1.3 \mathrm{~m} / \mathrm{s}$ the $17^{\text {th }}$ and the $21^{\text {st }}$ of July. The wind direction is notably changing, with three main directions: $25^{\circ}$ (North-East), on the $17^{\text {th }}, 360^{\circ}$ (North) on the $18^{\text {th }}, 205^{\circ}$ (SouthWest) from the $19^{\text {th }}$ to the $21^{\text {st }}$ and $305^{\circ}$ (North-West) at the end of the $21^{\text {st }}$ of July. 
The positive part of the difference between the two heat budgets occurs during a blowing of the wind from the North and North-East. The change of the wind direction (South-West), appeared on the $19^{\text {th }}$ of July, involves a drop in the percent of difference reaching $-8 \%$.

The Fig.7 shows the percentage of differences between BT1 and BT2 and the differences between the heat content of B1 (basin of the damn) and B2 (central basin), the two main volume basins. The two curves are related, especially from the middle of the $19^{\text {th }}$ of July. The relation of the curves shows coordination among the difference in heat budget and a difference in the heat content of the two deep basins. It works for the two maxima, especially when the curve reaches $-8 \%$ and a few hours later. The trend is marked by the two other basins during the fall of the end of the $18^{\text {th }}$ of July. The wind plays a major role in accentuating or diminishing the percentage of difference between the two heat budgets. The speed but especially the directions of the wind are the main factors of differences - on a few days' scale.
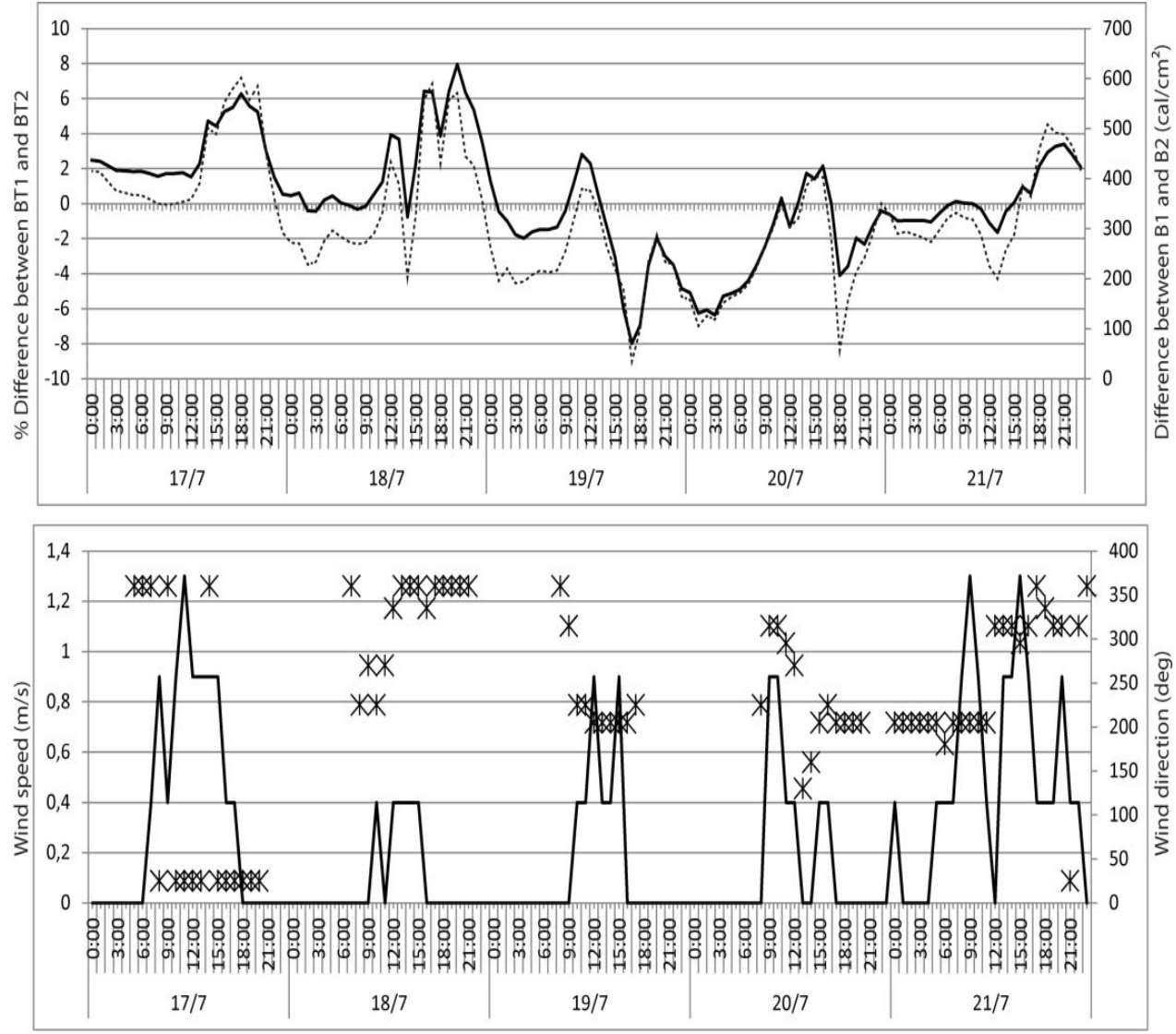

Fig. 7 Top: percentage of difference between BT1 and BT2 (Black line) and difference between B1 and B2 (dashed line). Bottom: wind speed (line) and direction (stars). From 17/07/2016 to 21/07/2016. 


\subsubsection{Daily study}

On a daily scale, the variation of the heat budget is consequent. The day of the 18th of July is one of the days where the heat content's amplitude was the highest (Fig. 8). The heat content's amplitude reached $521 \mathrm{cal} / \mathrm{cm}^{2}$ for BT1 and $360 \mathrm{cal} / \mathrm{cm}^{2}$ for BT2. The minimum and the maximum occurs at the same time for both heat contents, with a minimum at 8:00 and a maximum at the end of the day at 19:00. This amplitude can be named "the daily heat budget" of the pond. The daily heat budget reached its maximum in summer time, when the accumulation of solar radiation and the outside temperature are the highest. This budget changes very fast from one day to another, heavily influenced by the meteorological conditions.

The curve of the BT2 is smoother than BT1, with a similar minimum (2110 and 2106 $\mathrm{cal} / \mathrm{cm}^{2}$ respectively), and a strictly higher maximum for BT1 $\left(2470\right.$ and $2627 \mathrm{cal} / \mathrm{cm}^{2}$ respectively). This smoothing is partially due to the integration of all the basins of the pond in BT2. Hence, it limits the specificity of the measurements in one location, sheltered by wind or in the direction of the wind.

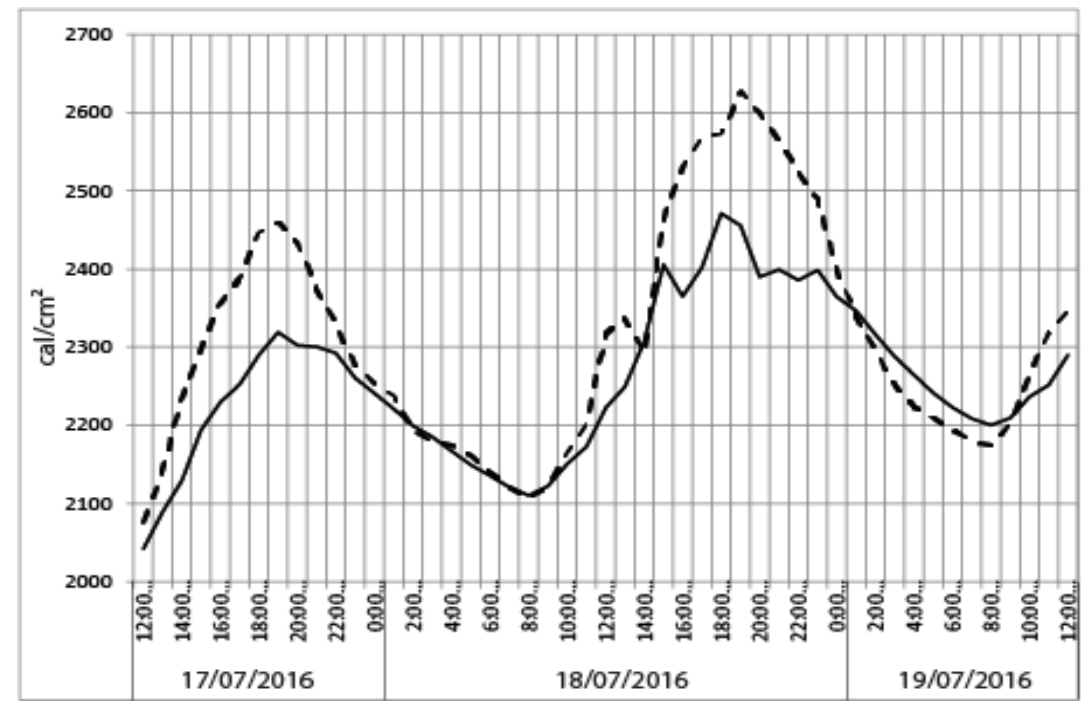

Fig. 8. Daily variation of the heat content from BT1 (dashed line) and BT2 (dark line).

\section{DISCUSSION}

\subsection{Vulnerability of ponds from meteorological conditions}

The results show a high dependence of the heat budget to the meteorological conditions. A rainy and cold spring leads to weak heat content at this time, while it is very high in July, where the weather was warm and dry. The heat content can rise and drop quickly, especially in these medium altitude mountains, where the air temperature amplitude between the day and the night can be high.

Ponds are an indicator of the last climate conditions, widely studied over the last decade. Meteorological conditions are also an important indicator on the thermal dynamic 
of the pond. The wind plays a major role in the thermal spatial heterogeneity over the water body, especially the ones with a complex shape. Ponds with a high shoreline index, especially due to the steep shoreline, are suitable to a spatial heterogeneity. The study of a smaller and round shaped pond (Etang du Château, Rilhac-Rancon, France, 0.4ha, 4.5m max depth) is in progress to learn the spatial repartition of temperature over the pond.

The differences in the thermal dynamic and the heat budget are various and important during the springtime. The first stratifications, during springtime, are weak and the wind can easily break it. During this time, even a small differentiation in the fetch can lead to a consequent difference into the thermal stratification over the different basins. B1, which is the source of calculation of BT1, is sheltered by a great part of the wind directions, at the opposite of B2, which concentrates the biggest volume, at the junction of almost all the winds. The differences between B1 and B2's temperatures are mainly due to the wind exposure. The wind's effect is also visible on B3, well sheltered by winds due to the narrowness of the basin, but also probably due to the vegetation sheltering, compared to B4, a bit less narrow but mainly less sheltered by vegetation (especially on the East part totally devoid of vegetation. See Fig. 1). Consequently, B4 concentrates the coldest water, weakly and rarely stratified, while B3 is frequently stratified in spite of the shallow water column. The localisation according to the dominant winds is important. The wind drive the warm surface water to the direction of the opposite shore. The differences between the two shores (and more broadly the basins) can reach $4^{\circ} \mathrm{C}$ between the windward basin cooler and the lee basin. The distribution of the heat deeper by the wind enhance the heat content of the pond at the lee basin. In contrast, a upwelling occur in the windward coast, reducing the heat content. In the central part, there is no such effect of upwelling and downwelling but the basin is more often affected by wind from any directions.

\subsection{The spatial and temporal scales: a solution to improve the heat budget?}

The heat budget is traditionally calculated from the deepest point, considering the representativeness of this point to the whole waterbody. When this budget is calculated from four points around the pond, according to the bathymetry and the fetch map, the differences between the two heat budgets can be consequent. These differences vary with time and meteorological conditions. It is highest when a strong stratification occurs during summer. It can be partly explained by the difference in the temperature of B1 and B2, the two main volumetric parts of the pond. When B2 is colder than B1, which happens very often, especially under windy conditions, BT1 is overestimated. With a wind from the North, the $19^{\text {th }}$ of July for example, the underestimation of the BT1 is not due only to B2B1, but mainly to the increase of the heat content of B3 and B4, sheltered by North-wind.

B1 and B2 play a major role into the precision of the heat content of the pond. B3 and B4, for their part, can play, in some events, an important role improving the heat content. All of these factors seems to be due to the wind heterogeneity around the pond.

The temperature and heat content of a polymmictic lake is changing fast. The temperature can be different from a place to another but also from a day to another or within a day. At a daily scale, the main heat content differences between the two methods seem to take place at the end of the day, when the stratification and the warming are at their maximum. On the opposite, it is during the morning, at 8:00 principally, when the warming has done nothing yet and the previous heat content is attenuated by the cooling, that the marge of error of BT1 is the lowest.

In order to enhance the knowledge of the heat content of the waterbodies, it would be useful to take continuous temperature data, for as long as possible. The days with no wind 
are useful for this type of waterbody. The wind-induced variations are the main factor on La Ramade pond because of it complex morphology and well-developed shoreline. It is different with great lakes and also with very small ponds, as L'Etang du Château (0.4ha, $4.5 \mathrm{~m}$ max depth), where the first results shows the importance of the direct radiation, where temperature differences are caused by a shaded area of the pond (Choffel, ongoing study).

\section{CONCLUSION}

The heat content is a very important component of the evaluation of water quality. This methodology allows to understand the heat dynamic of the pond taking into account the vertical and horizontal variations. In other studies the evaluation of the heat content is based on data from one point, usually the deepest point of the pond. The temporal and spatial variation of temperature can causes a high percentage of error between traditional and spatially-based methods. Because of the wind heterogeneity through the pond, it is suitable to take temperature data on several points of the pond. Temporal variations, daily or weekly, linked to the meteorological conditions lead to take continuous data in order to reduce the percentage of error. The pond of La Ramade, with a complex morphology and a well-developed shoreline induces the spatial heterogeneity. This kind of morphology is common in France and Europe when a dam bar a river. The forthcoming work will be to compare with other ponds of different and simpler morphology and have an estimation of the heat budget of the French ponds, according to the inventory work and volume correlation of Bartout \& Touchart (2013).

\section{R E F E R E N C ES}

Bartout, P. (2015) Les territoires limniques. Nouveau concept limnologique pour une gestion géographique des milieux lentiques. Orléans, université d'Orléans.

Bartout, P. \& Touchart, L. (2013) L'inventaire des plans d'eau français : outil d'une meilleure gestion des eaux de surface. Annales de géographie, 691 (3), 266.

Bartout P., Touchart L., Terasmaa J., Choffel Q., Marzecova A., Koff T., Kapanen G., Qsair Z., Maleval V., Millot C., Saudubray J. \& Aldomany M. (2015) A new approach to inventorying bodies of water, from local to global scale. Die Erde- journal of the Geographical Society of Berlin, 146 (4), 245-258.

Birge, E. A. (1909) An unregarded factor in lake temperatures. Wisconsin Academy of Sciences, Arts, and Letters, 5, 989-1017.

Birge, E. A. (1915) The Heat Budgets of American and European Lakes. Transactions of the Wisconsin Academy of Sciences, Arts, and Letters, 166-213.

Birge, E. A. (1916) The Work of the Wind in Warming a Lake. Transactions of the Wisconsin Academy of Sciences, Arts, and Letters, 8, 341-391.

Birge, E. \& Juday, C. (1914) A Limnological Study of the Finger Lakes of New York. Wisconsin Geological and Natural History Survey Report.

Céréghino, R., Box, D., Cauchie, H.M., Martens, K. \& Oerli, B. (2013) The ecological rôle of ponds in changinf world. Hydrobiologia, 723 (1), 1-6.

Downing, J. A. (2010) Emerging Global Role of Small Lakes and Ponds: Little Things Mean a Lot. Limnetica, 1 (29), 9-24.

Folkard, A. M., Sherborne, A. M. \& Coates, M. J. (2007) Turbulence and Stratification in Priest Pot, a Productive Pond in a Sheltered Environment, Limnology, 8 (2), 113-20.

Forel, F. A. (1892) Le Léman, Monographie Limnologique. Lausanne, F. Rouge, T.I. 
Gorham, E. (1964) Morphometric Control of Annual Heat Budgets in Temperate Lakes. Limnology and Oceanography, 9 (4), 525-29.

Humbert, L. (2014) Réalisation de diagnostic physico-chimiques, chimiques, hydromorphologiques et biologiques. Etang de la Ramade FRFL82. Report CF123-02, Aquabio.

Hutchinson, G. E. (1957) Treatise on Limnology. New York, Jonh Wiley \& sons, INC.

Imberger, J. (1985) The Diurnal Mixed layer. Limnology and Oceanography, 30 (4), 737-70.

Imberger, J. \& Parker, G. (1985) Mixed Layer Dynamics in a Lake Exposed to a Spatially Variable Wind Field. American Society of Limnology and Oceanography, 30 (3), 473-788.

Joly, D., Brossard, T., Cardot, H., Cavailhes, J., Hilal, M. \& Wavresky, P. (2010) Les Types de Climats En France, Une Construction Spatiale. Cybergeo: European journal of Geography. [Online] Available from: http://cybergeo.revues.org/23155 [Accessed 24th July 2016].

Liu, W., Bocaniov, S. A., Lamb, K.G. \& Smith, R. A. (2014) Three Dimensional Modeling of the Effects of Changes in Meteorological Forcing on the Thermal Structure of Lake Erie. Journal of Great Lakes Research, 40 (4), 827-40.

Markfort, C. D., Perez, A. L. S., Thill, J. M., Jaster, D. A., Porté-Agel, F. \& Stefan, H. G. (2010) Wind sherltering of a lake by a tree canopy or bluff topography. Water Resources Research, 46 (3), 1-13.

Murphy, S., Collins, N. \& Doka, S. E. (2012) Determinants of Temperature in Small Coastal Embayments of Lake Ontario. Journal of Great Lakes Research, 38 (4), 600-609.

Papon, P. (2007) Les Plans D'eau Superficiels: Définition, Fonctionnement et Aménagement. Limoges, Université de Limoges.

Ragotzkie, R. A. (1978) Heat Budgets of Lakes, in Lakes: Chemistry, Geology, Physics, Springer, 118. New York: Abraham Lerman.

Ramos, A. (2012) Hidrometeorología y balance térmico de la marisma de Doñana. Barcelone, Universitat Politécnica de Catalunya.

Rueda, F.J. \& Cowen, E. A. (2005) Exchange between a Freshwater Embayment and a Large Lake through a Long Shallow Channel. Limnology and Oceanography, 50 (1), 169-83.

Saur, J.F.T. \& Anderson, E.R. (1956) The heat budget of a body of water of varying volume. Limnology and Oceanography, 4 (1), 247-251.

Stewart, K. M. (1973) Detailed Time Variations in Mean Temperature and Heat Content of Some Madison Lake. Limnology and Oceanography, 18 (2), 218-26.

Touchart, L. (2002) Limnologie Physique et Dynamique. Paris, Harmattan.

Touchart, L. (2016) Le Bilan Thermique Des étangs: Réflexion épistémologique et Application Aux étangs Limousins. Annales de Géographie, 125 (708), 143-169.

Verpoorter, C., Kutser, T., Seekell, D. \& Tranvik, L. J. (2014) A global inventory of lakes based on high-resolution sattelite imagery. Geophysical Research Letters, 41 (18), 6396-6402.

Wang, W., Xiao, W., Cao, C., Gao, Z., Hu, Z., Liu, S., Shen, S., Wang, L., Xiao, Q., Xu, J., Yang, D. \& Lee, X. (2014) Temporal and Spatial Variations in Radiation and Energy Balance across a Large Freshwater Lake in China. Journal of Hydrology, 511, 811-24.

Wedderburn, E. M. (1910) Temperature of Scottish lakes. Bathymetrical Survey of the Fresh-Water Lochs of Scotland, 1897-1909, I, 91-144.

Wetzel, R. G. (1983) Limnology. Second edition. Michigan State University: Saunders college publishing.

Williams, P., Whitfield, M., Biggs, J., Bray, S., Fox, G., Nicolet, P., \& Sear, D. (2003) Comparative Biodiversity of Rivers, Streams, Ditches and Ponds in an Agricultural Landscape in Southern England. Biological Conservation, 115 (2), 329-41.

Xing, Z., Fong, D.A, Tan, K.M., Lo, E.Y-M. \& Monismith, S. G. (2012) Water and Heat Budgets of a Shallow Tropical Reservoir. Water Resources Research, 48 (6). 